\title{
Comparative Study of Various Seismic Analysis Methods for Rc Structure
}

\author{
Wahane Rasika Murlidhar*, Phuke Rahul M.** \\ *(Department of Civil/Structure, SSGB Amravati University, Amravati, India \\ Email: Rasikawahane16@gmail.com) \\ ** (Department of Civil/Structure, SSGB Amravati University, Amravati, India \\ Email:phukerm@gmail.com)
}

\begin{abstract}
A large number of RC frame buildings have been built in India in recent years. Huge number of similarly designed and constructed buildings exist in the various towns and cities situated in moderate to severe seismic zones of the country. Analysis and design of such buildings for static forces is a routine affair these days because of availability of affordable computers and specialized programs which can be used for the analysis. On the other hand, dynamic analysis is a time consuming process and requires additional input related to mass of the structure, and an understanding of structural dynamics for interpretation of analytical results. Reinforced Concrete (RC) frame buildings are most common type of constructions in urban India, which are subjected to several types of forces during their lifetime, such as static forces due to dead and live loads and dynamic forces due to earthquake. To ensure safety against seismic forces of multi-storied building hence, there is need to study of seismic analysis to design earthquake resistance structures. In the present study a multi-storied framed structure is selected, And Linear seismic analysis is done for the building by static method (Equivalent Static Method) and dynamic method (Response Spectrum Method \& Time history Method) using ETAB2016 as per the IS-1893-2002-Part-1. As a result, the response of structure has been obtained for considered building models, based on each methods of analysis, and then the results are compared with each other.
\end{abstract}

Key: RC structure, seismic analysis, Equivalent Static, Response Spectrum and time history analysis, Displacement, Acceleration, base shear.

\section{INTRODUCTION}

An Earthquake is Earth's Shaking or in other words release of energy due to the movement of tectonic plates. This can be destructive enough to kill thousands of people and bring huge economic loss. This natural disaster has many adverse effects on earth like ground shaking, landslides, rock falls from cliffs, liquefaction, fire, tsunami etc. Buildings are highly affected by an earthquake, and in some cases they are shattered down to the ground level. When the ground shaking occurs beneath the building's foundations they vibrate in an analogous manner with that of the surrounding ground. The inertia force of a structure can develop shearing effect on it which in turn causes stress concentration on the connections in structure and on the fragile walls. This results in partial or full failure of structure. The excitement and prevalence of shaking depends on the orientation of the building. High rise structures have the tendency to magnify the magnitude of long time periodic motions when comparing to the smaller one. Every construction has a resonant prevalence which are the characteristics of structure. Taller buildings have a tendency for long time periods than shorter one which make them relatively more susceptible to damage. Hence, one has to be careful while performing the analysis of a tall structure. In order to analyse a tall structure mainly three analysis procedures are valid like a) Equivalent static analysis, b) Response spectrum analysis, c) Time history analysis. Soil structure interaction analysis is also essential to be considered. After identifying the soil type analysing procedure is selected to do the detailed analysis of the interaction between soil and structure. To reduce the seismic effects on tall buildings several equipment is used like dampers or base isolation process. In dampers viscous damper, friction damper, yielding damper, magneto rheological fluid dampers tuned mass damper or harmonic absorber can be used.

The main objective of this project is to study the seismic behavior and damage of concrete reinforced building. Also, analysis of structure by using equivalent static method, response spectrum method and time history method has been surveyed based on IS codes; The maximum storey displacements result have been obtained by using all methods of analysis and compared to displacement capacity of building to assess the damage of building. 


\subsection{SEISMIC ANALYSIS METHODS:}

Seismic analysis is a major tool in earthquake engineering which is used to understand the response of buildings due to seismic excitations in a simpler manner. In the past the buildings were designed just for gravity loads and seismic analysis is a recent development. It is a part of structural analysis and a part of structural design where earthquake is prevalent.

There are different types of earthquake analysis methods. Some of them used in the project are-

I. Equivalent Static Analysis

II. Response Spectrum Analysis

III. Time History Analysis

\subsubsection{EQUIVALENT STATIC ANALYSIS:}

The equivalent static analysis procedure is essentially an elastic design technique. It is, however, simple to apply than the multi-model response method, with the absolute simplifying assumptions being arguably more consistent with other assumptions absolute elsewhere in the design procedure.

\subsubsection{RESPONSE SPECTRUM ANALYSIS:}

This approach permits the multiple modes of response of a building to be taken into account. This is required in many building codes for all except for very simple or very complex structures. The structural response can be defined as a combination of many modes. Computer analysis can be used to determine these modes for a structure. For each mode, a response is obtained from the design spectrum, corresponding to the modal frequency and the modal mass, and then they are combined to estimate the total response of the structure. In this the magnitude of forces in all directions is calculated and then effects on the building is observed

\subsubsection{TIME HISTORY ANALYSIS:}

Time history analysis techniques involve the stepwise solution in the time domain of the multidegree-of-freedom equations of motion which represent the actual response of a building. It is the most sophisticated analysis method available to a structural engineer. Its solution is a direct function of the earthquake ground motion selected as an input parameter for a specific building. This analysis technique is usually limited to checking the suitability of assumptions made during the design of important structures rather than a method of assigning lateral forces themselves.

\section{ANALYTICAL WORK}

Building consists of $16 \mathrm{~m}$ in both $\mathrm{X}$ direction and Y-direction for Static (Model1:Equivalent Static Analysis) and Dynamics Analysis (Model2: Response Spectrum and Model3
Time History Analysis) on computer program ETABS2016 to studied seismic behavior of structure for globally considered models, so from preliminary design the sizes of various structural members were estimated as follows

Brick masonry wall Thickness: $230 \mathrm{~mm}$

Storey height: $3 \mathrm{~m}$ for all floors

Grade of steel: Fe-500

Grade of concrete: $\mathrm{M}-25$

Column Size: $450 \mathrm{X} 450 \mathrm{~mm}$

Beam Size: 450X 450mm

Slab thickness: $150 \mathrm{~mm}$

Dead Load (DL):

Intensity of wall $($ Ext. \& Int. wall $)=13.11 \mathrm{KN} / \mathrm{m}$

Intensity of floor finish load $=1 \mathrm{KN} / \mathrm{m}^{2}$

Intensity of roof treatment load $=1 \mathrm{KN} / \mathrm{m}^{2}$

Live load (LL):

Intensity of live load $=3 \mathrm{KN} / \mathrm{m}^{2}$

Lateral loading (IS 1893 (Part I):2002):

Building under consideration is in Zone $-\mathrm{V}$

Period Calculation: Program Calculated

Top Storey: Storey- 10

Bottom Storey: Ground Floor or Base

Response reduction factor, $\mathrm{R}=5$

Importance factor, $\mathrm{I}=1$

Building Height $\mathrm{H}=30 \mathrm{~m}$

Soil Type = II (Medium Soil)

Seismic zone factor, $Z=0.36$

Ground Motion Database: Matched To Response Spectrum

Time history motion type: Transient

Case: EQX and EQY

$$
\text { Spec X and Spec Y }
$$$$
\text { THX and THY }
$$

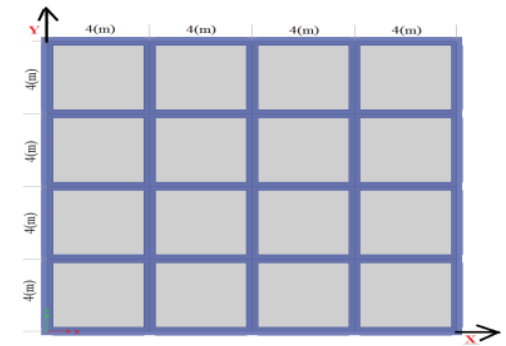

Fig.1: Plan of structure

\section{RESULTS AND DISCUSSION}

3.1Maximum Lateral Displacement

\begin{tabular}{|l|c|c|c|}
\hline \multicolumn{4}{|c|}{ Table1: Maximum displacement of Model1 } \\
\hline $\begin{array}{l}\text { Storey } \\
\text { No's }\end{array}$ & $\begin{array}{l}\text { Storey } \\
\text { Height }(\mathrm{m})\end{array}$ & EQX $(\mathrm{mm})$ & EQY(mm) \\
\hline Story10 & 30 & 80.804 & 80.804 \\
\hline Story9 & 27 & 77.319 & 77.319 \\
\hline Story8 & 24 & 71.85 & 71.85 \\
\hline Story7 & 21 & 64.71 & 64.71 \\
\hline Story6 & 18 & 56.302 & 56.302 \\
\hline Story5 & 15 & 46.986 & 46.986 \\
\hline Story4 & 12 & 37.078 & 37.078 \\
\hline
\end{tabular}




\begin{tabular}{|c|c|c|c|} 
Story3 & 9 & 26.846 & 26.846 \\
\hline Story2 & 6 & 16.541 & $1.65 \mathrm{E}+01$ \\
\hline Story1 & 3 & 6.637 & 6.637 \\
\hline Base & 0 & 0 & 0 \\
\hline
\end{tabular}

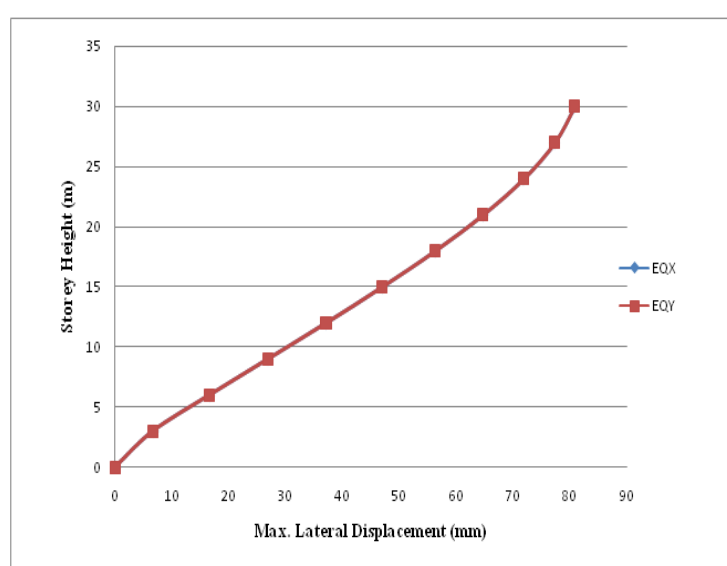

Graph 1: Maximum displacement of Model1 with respect to height.

Table2: Maximum displacement of Model2

\begin{tabular}{|c|c|c|c|}
$\begin{array}{l}\text { Storey } \\
\text { No's }\end{array}$ & $\begin{array}{l}\text { Storey } \\
\text { Height } \\
(\mathrm{m})\end{array}$ & SPECX $(\mathrm{mm})$ & SPECY $(\mathrm{mm})$ \\
\hline Story10 & 30 & 25.231 & 25.231 \\
\hline Story9 & 27 & 24.327 & 24.327 \\
\hline Story8 & 24 & 22.905 & 22.905 \\
\hline Story7 & 21 & 21.011 & 21.011 \\
\hline Story6 & 18 & 18.711 & 18.711 \\
\hline Story5 & 15 & 16.052 & 16.052 \\
\hline Story4 & 12 & 13.058 & 13.058 \\
\hline Story3 & 9 & 9.753 & 9.753 \\
\hline Story2 & 6 & 6.181 & 6.181 \\
\hline Story1 & 3 & 2.533 & 2.533 \\
\hline Base & 0 & 0 & 0 \\
\hline
\end{tabular}

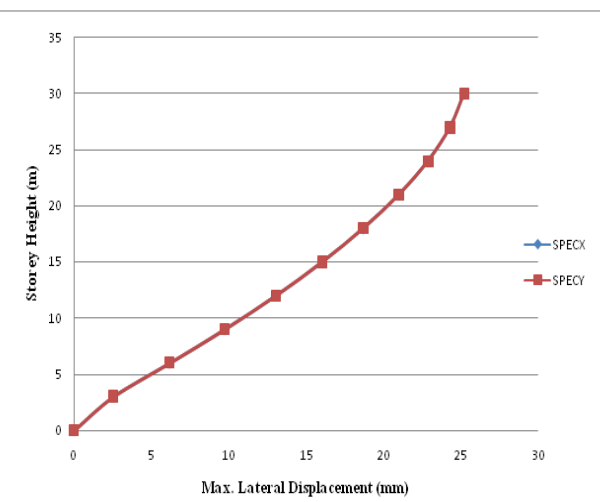

Graph 2: Maximum displacement of Model2 with respect to height
Table3: Maximum displacement of Model3(Back \& Forth form in X direction)

\begin{tabular}{|l|c|c|c|}
\hline $\begin{array}{l}\text { Storey } \\
\text { No's }\end{array}$ & $\begin{array}{l}\text { Storey } \\
\text { Height }(\mathrm{m})\end{array}$ & $\begin{array}{l}\text { THX } \\
\max (\mathrm{mm})\end{array}$ & $\begin{array}{l}\text { THX } \\
\min (\mathrm{mm})\end{array}$ \\
\hline Story10 & 30 & 24.373 & -25.462 \\
\hline Story9 & 27 & 23.268 & -23.931 \\
\hline Story8 & 24 & 21.483 & -22.492 \\
\hline Story7 & 21 & 19.495 & -20.698 \\
\hline Story6 & 18 & 17.313 & -18.289 \\
\hline Story5 & 15 & 14.776 & -15.516 \\
\hline Story4 & 12 & 11.918 & -12.921 \\
\hline Story3 & 9 & 8.8 & -9.686 \\
\hline Story2 & 6 & 5.632 & -6.079 \\
\hline Story1 & 3 & 2.318 & -2.457 \\
\hline Base & 0 & 0 & 0 \\
\hline
\end{tabular}

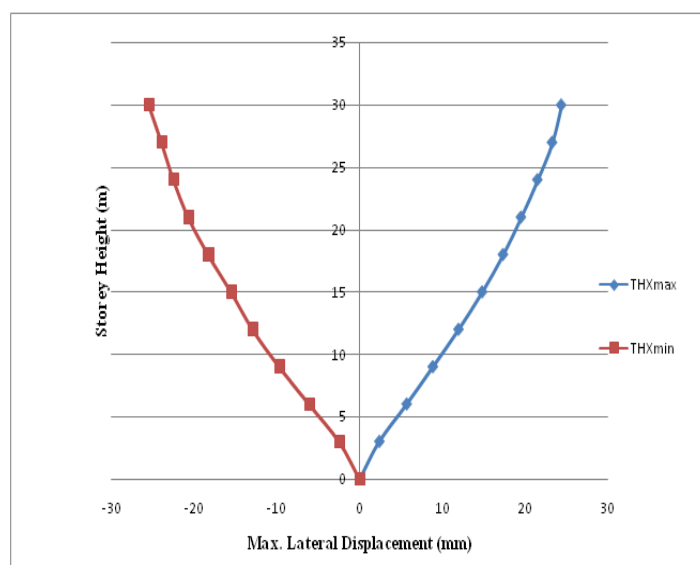

Graph 3: Maximum displacement of Model3 with respect to height in X-dir.

Table4: Maximum displacement of Model3(Back \& Forth form in Y direction)

\begin{tabular}{|l|c|c|c|}
\hline $\begin{array}{l}\text { Storey } \\
\text { No's }\end{array}$ & $\begin{array}{l}\text { Storey } \\
\text { Height }(\mathrm{m})\end{array}$ & $\begin{array}{l}\text { THY } \\
\max (\mathrm{mm})\end{array}$ & $\begin{array}{l}\text { THY } \\
\min (\mathrm{mm})\end{array}$ \\
\hline Story10 & 30 & 24.373 & -25.462 \\
\hline Story9 & 27 & 23.268 & -23.931 \\
\hline Story8 & 24 & 21.483 & -22.492 \\
\hline Story7 & 21 & 19.495 & -20.698 \\
\hline Story6 & 18 & 17.313 & -18.289 \\
\hline Story5 & 15 & 14.776 & -15.516 \\
\hline Story4 & 12 & 11.918 & -12.921 \\
\hline Story3 & 9 & 8.8 & -9.686 \\
\hline Story2 & 6 & 5.632 & -6.079 \\
\hline Story1 & 3 & 2.318 & -2.457 \\
\hline Base & 0 & 0 & 0 \\
\hline
\end{tabular}




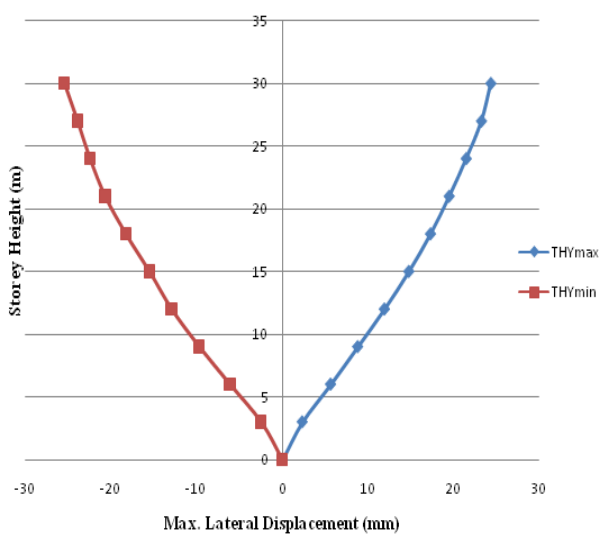

Graph 4: Maximum displacement of Model3 with respect to height in Y-dir

Table5: Comparison of Model 1, $2 \& 3$

Maximum displacement in $\mathrm{X}$ or $\mathrm{Y}$-direction

\begin{tabular}{|c|c|c|c|c|}
\hline Storey & $\begin{array}{c}\text { Storey } \\
\text { Height } \\
(\mathrm{m})\end{array}$ & $\begin{array}{c}\text { Model } \\
1(\mathrm{~mm})\end{array}$ & $\begin{array}{c}\text { Model } \\
2(\mathrm{~mm})\end{array}$ & $\begin{array}{c}\text { Model } \\
3(\mathrm{~mm})\end{array}$ \\
\hline Story10 & 30 & 80.804 & 25.231 & 25.462 \\
\hline Story9 & 27 & 77.319 & 24.327 & 23.931 \\
\hline Story8 & 24 & 71.85 & 22.905 & 22.492 \\
\hline Story7 & 21 & 64.71 & 21.011 & 20.698 \\
\hline Story6 & 18 & 56.302 & 18.711 & 18.289 \\
\hline Story5 & 15 & 46.986 & 16.052 & 15.516 \\
\hline Story4 & 12 & 37.078 & 13.058 & 12.921 \\
\hline Story3 & 9 & 26.846 & 9.753 & 9.686 \\
\hline Story2 & 6 & 16.541 & 6.181 & 6.079 \\
\hline Story1 & 3 & 6.637 & 2.533 & 2.457 \\
\hline Base & 0 & 0 & 0 & 0 \\
\hline
\end{tabular}

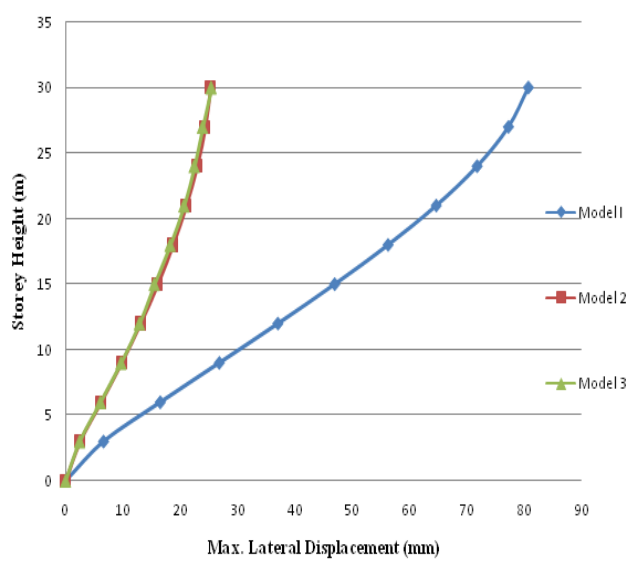

Graph 5: Maximum displacement of Model 1, 2 \& 3 with respect to height.

\subsection{Natural Period and Acceleration: \\ 3.2.1 Natural Period and Acceleration values for Response Spectrum Analysis}

\begin{tabular}{|c|c|c|c|c|}
\hline \multicolumn{4}{|c|}{ Table 6: Acceleration values for particular natural } \\
period of Model 2
\end{tabular}

Table 6 shows, acceleration values are obtained in first mode and it gives values with considered seismic intensity of zones. After the first mode acceleration value will increase till the constant value before stop vibrating the structure. The reason for this to happen is that long duration earthquake with high peak ground acceleration (PGA) have more energy flux and it takes long time for the structure to dissipate energy. The energy gets dissipated after getting transferred up to full length of structure hence the top portion has maximum acceleration.

3.2.2 Natural Period and Acceleration values for Time History Analysis:

\begin{tabular}{|c|c|c|c|}
\hline \multicolumn{4}{|c|}{ Table 7: } \\
\hline Period & $\begin{array}{c}\text { Damping } \\
0.03\end{array}$ & Damping 0.05 & Damping 0.07 \\
\hline & SA & SA & SA \\
\hline sec & $\mathrm{m} / \mathrm{sec}^{2}$ & $\mathrm{~m} / \mathrm{sec}^{2}$ & $\mathrm{~m} / \mathrm{sec}^{2}$ \\
\hline 0.2 & 0.12 & 0.12 & 0.12 \\
\hline 0.3 & 0.28 & 0.26 & 0.25 \\
\hline 0.4 & 0.49 & 0.44 & 0.4 \\
\hline 0.5 & 0.91 & 0.84 & 0.79 \\
\hline 0.6 & 2.78 & 2.12 & 1.71 \\
\hline 0.641 & 3.13 & 2.41 & 1.98 \\
\hline 0.7 & 2.61 & 2.15 & 1.83 \\
\hline 0.728 & 2.31 & 1.95 & 1.68 \\
\hline 0.8 & 1.55 & 1.42 & 1.31 \\
\hline 0.9 & 1.16 & 1.08 & 1.01 \\
\hline 1 & 1.14 & 1.04 & 0.96 \\
\hline 1.1 & 1.16 & 1.05 & 0.96 \\
\hline 1.2 & 1.05 & 0.96 & 0.88 \\
\hline
\end{tabular}




\begin{tabular}{|c|c|c|c|}
\hline \multicolumn{4}{|c|}{ Table 7: } \\
\hline Period & $\begin{array}{c}\text { Damping } \\
0.03\end{array}$ & Damping 0.05 & Damping 0.07 \\
\hline & SA & SA & SA \\
\hline $\mathrm{sec}$ & $\mathrm{m} / \mathrm{sec}^{2}$ & $\mathrm{~m} / \mathrm{sec}^{2}$ & $\mathrm{~m} / \mathrm{sec}^{2}$ \\
\hline 1.3 & 1.04 & 0.92 & 0.85 \\
\hline 1.4 & 1.1 & 1.02 & 0.96 \\
\hline 1.5 & 1.38 & 1.25 & 1.14 \\
\hline 1.6 & 1.48 & 1.3 & 1.15 \\
\hline 1.8 & 1.95 & 1.57 & 1.3 \\
\hline 1.957 & 2.49 & 2.04 & 1.72 \\
\hline 2 & 2.59 & 2.1 & 1.76 \\
\hline 2.2 & 2.08 & 1.86 & 1.69 \\
\hline 2.212 & 2.05 & 1.84 & 1.67 \\
\hline 2.4 & 1.41 & 1.25 & 1.21 \\
\hline 2.6 & 1.08 & 1.06 & 1.04 \\
\hline 2.8 & 1.1 & 1.09 & 1.08 \\
\hline 3 & 1.27 & 1.18 & 1.12 \\
\hline 3.3 & 1.64 & 1.32 & 1.13 \\
\hline 3.398 & 1.67 & 1.34 & 1.14 \\
\hline 3.6 & 1.54 & 1.4 & 1.29 \\
\hline 3.778 & 1.48 & 1.34 & 1.24 \\
\hline 4 & 1.13 & 1.07 & 1.04 \\
\hline 4.4 & 1.01 & 0.96 & 0.93 \\
\hline 4.7 & 1.05 & 0.87 & 0.83 \\
\hline 4.906 & 0.89 & 0.87 & 0.87 \\
\hline 5 & 0.89 & 0.89 & 0.88 \\
\hline 5.438 & 1.09 & 1.02 & 0.98 \\
\hline 5.5 & 1.13 & 1.04 & 0.98 \\
\hline 6 & 0.76 & 0.81 & 0.83 \\
\hline 6.5 & 0.65 & 0.74 & 0.79 \\
\hline 7 & 1.03 & 0.96 & 0.92 \\
\hline 7.5 & 0.86 & 0.9 & 0.92 \\
\hline 8 & 1.03 & 0.99 & 0.97 \\
\hline 8.5 & 1.01 & 0.99 & 0.97 \\
\hline 9 & 0.92 & 0.93 & 0.93 \\
\hline 10 & 0.89 & 0.89 & 0.89 \\
\hline 11 & 0.86 & 0.85 & 0.86 \\
\hline 12 & 0.81 & 0.83 & 0.85 \\
\hline 13 & 0.85 & 0.88 & 0.88 \\
\hline 14 & 0.91 & 0.9 & 0.89 \\
\hline 15 & 0.89 & 0.89 & 0.89 \\
\hline 16.5 & 0.85 & 0.87 & 0.88 \\
\hline 18 & 0.92 & 0.91 & 0.9 \\
\hline 20 & 0.89 & 0.89 & 0.89 \\
\hline 22 & 0.86 & 0.87 & 0.88 \\
\hline 25 & 0.89 & 0.89 & 0.89 \\
\hline 28 & 0.9 & 0.9 & 0.89 \\
\hline 33 & 0.88 & 0.88 & 0.88 \\
\hline
\end{tabular}

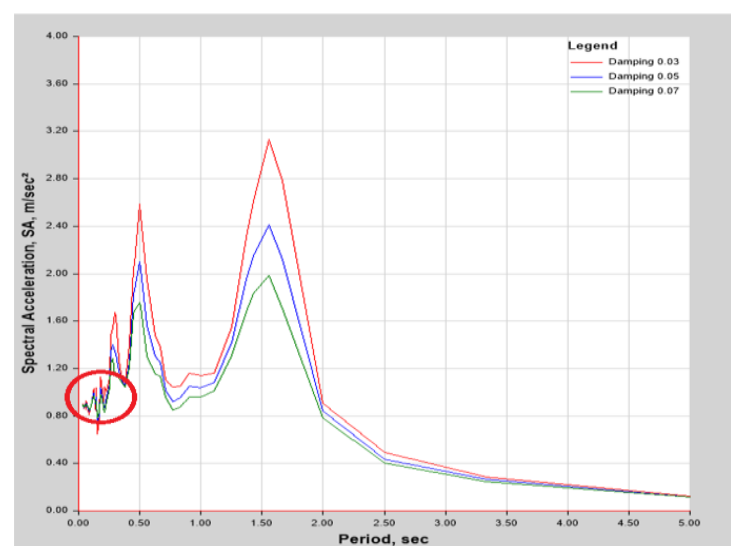

Graph 6: Spectral Acceleration varies with Period for different damping ratio

Graph 6 shows the region of red circle marked slight change in nature period can lead to large variation in maximum acceleration. The effect of damping on the resonant response is seen clearly, the lower is the damping value, the bigger the response

\subsection{Base Shear:}

Table8: Comparision of Base Shear for Models 1, 2 \& 3

\begin{tabular}{|c|c|c|c|}
\hline Model & Analysis & X-dir. $(\mathrm{KN})$ & Y-dir. $(\mathrm{KN})$ \\
\hline Model 1 & ESA & 3325.3457 & 3325.3457 \\
\hline Model 2 & RSA & 1287.693 & 1287.693 \\
\hline Model 3 & THA & 1235.1789 & 1235.1789 \\
\hline
\end{tabular}

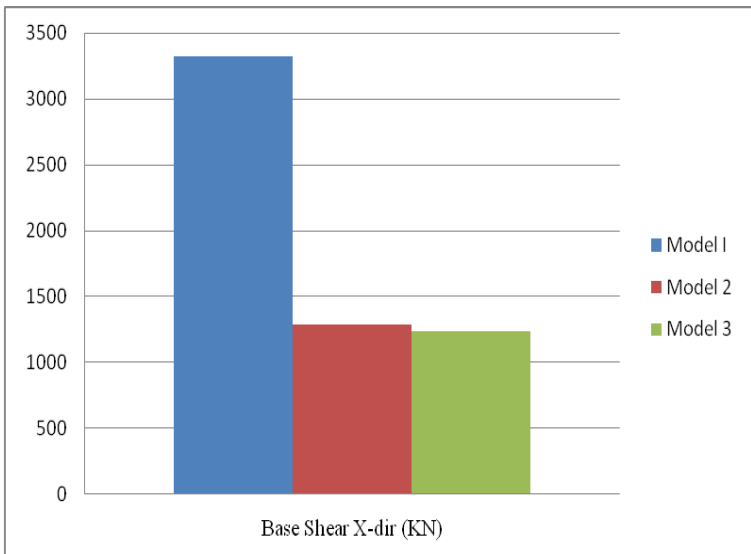

Graph 7: Maximum Base Shear along X dir. or Y dir. For all considered Models

\begin{tabular}{|c|c|c|c|c|}
\hline \multicolumn{4}{|c|}{ Table9:Base Shear from Time History response } \\
output for a specified load case \\
\hline Model & \multicolumn{2}{|c|}{ X-direction } & \multicolumn{2}{|c|}{ Y-direction } \\
\hline \multirow{3}{*}{ Model } & Base & Base & Time \\
3 & Shear & Time & Shear & $(\mathrm{Sec})$ \\
& $(\mathrm{KN})$ & $(\mathrm{Sec})$ & $(\mathrm{KN})$ & \\
\cline { 2 - 5 } & 1235.17 & 2.9 & -1184.50 & 3.7 \\
\hline
\end{tabular}




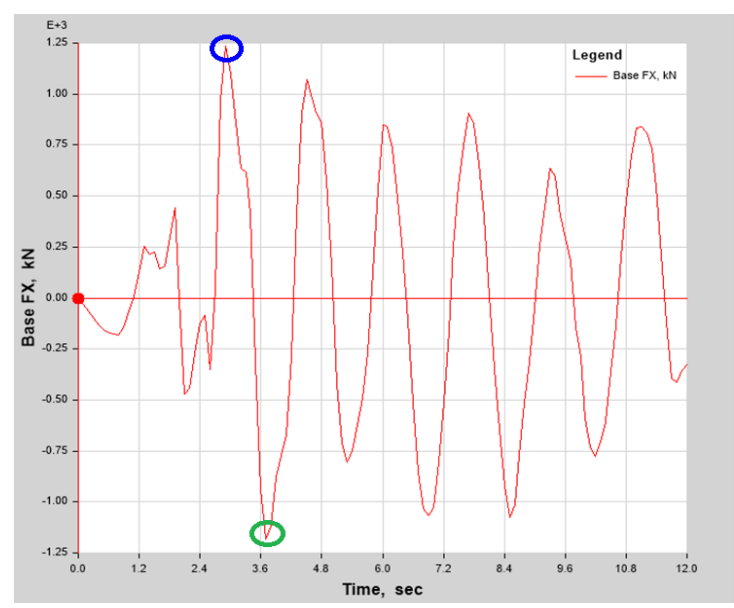

Graph 8: Base Shear from Time History response output for a specified load case

The Indian code distributes the base shear force to the floor levels by the proportions of the weighted average of the square of the height of the floor; in considered models here height and assigning weight are same for all cases only seismic analysis of structure has been change. In Graph 9.10 shows base shear values of structure in particular time interval for back and forth direction during acceleration flux vibrates the structure globally.

A quantitative comparison of the base shear for three models is presented. However their seismic performance during the seismic time period interval will vary. Although the three analysis have different attributes, they all have acceptable performance and are expected to behave desirably in seismic events.

\subsection{Modal Load Participation ratio for all} Models:

\begin{tabular}{|c|c|c|c|c|}
\hline Case & Item Type & Item & $\begin{array}{c}\text { Static } \\
\%\end{array}$ & $\begin{array}{c}\text { Dynamic } \\
\%\end{array}$ \\
\hline Modal & Acceleration & UX & 99.98 & 97.03 \\
\hline Modal & Acceleration & UY & 99.98 & 97.03 \\
\hline
\end{tabular}

As per code IS 1893: 2002 clause 7.8.4.2 page 25 , The number of modes to be used should be such that the sum of total of modal masses of all modes considered is at least $90 \%$ of total seismic mass in IS code of practices. In the present study, the initial modes are found to be in translation for all structural system based on various codes of practices and excite more than $90 \%$ of the total mass. All the above considered models are satisfied the clause.

\section{CONCLUSION}

This study leads to following conclusion

1. As a result of comparison between three mentioned analysis it is observed that the displacement obtained by static analysis are higher than dynamic analysis including response spectrum and time history analysis.

2. The spectral acceleration verces period is used to define the acceleration values in the both directions, i.e. THX and THY, to account for the directional uncertainty of the earthquake motions and the low probability of simultaneous occurrence of the maximum response for each direction, the timehistory method allows a much more complete analysis because it provides the time evolution of any kind of result. For important structures time history analysis should be perform as it predicts the structural response more accurately in comparison with other two methods.

3. An increase in time duration of strong motion causes the response spectra to be flatter and have smaller slope, so for most periods an increase in time duration causes greater spectral values.

4. From results and discussion chapter, Linear static analysis of structures can be used for regular structures of limited height as in this process lateral forces are calculated as per code based fundamental time period of the structure. Linear dynamic analysis are an improvement over linear static analysis, as this analysis produces the effect of the higher modes of vibration and the actual distribution of forces in the elastic range in a better way.

5. Static analysis is not sufficient for high rise building and its necessary to provide dynamic analysis. The results of equivalent static analysis are approximately uneconomical because values of displacement are higher than dynamic analysis.

6. A quantitative comparison of the base shear for three models is presented. Their seismic performance during the seismic time period interval has been vary. Although the three analysis have different attributes, they all have acceptable performance and are expected to behave desirably in seismic events.

7. Suitable methods of analysis are provided in codes of practice; in general, the more complex and tall the building, the more stringent the analysis that is required. The linear time history method has huge potential to improve seismic performance in that dynamic amplification effects due to yielding are explicitly included in the evaluation.

\section{ACKNOLEDGEMENT}

Author of this article would like to thank Principal, HOD and all the staff of College of engineering \& technology Akola. Sant Gadge baba Amravati University, Amravati for support and opportunity.

\section{REFERENCES}

[1] Mrunmayi Gursale and P.S. Patil, Comparative parametric study of linear and nonlinear behavior of multistory structures, International Journal of Research in 
Engineering and Technology, Volume: 04 Issue: 04 | Apr-2015.

[2] Saurabh Lonkar and Prof. Riyaz Sameer Shah, Comparative study of static and dynamic analysis of multistorey regular \& irregular building, International Journal of Research in Engineering science and Technology, Volume: 01 Issue: 08 | Dec 2015.

[3] Aniruddha Gottala, Kintali Sai Nanda Kishor and Dr.Shaik Yajdhani, comparative study of static and dynamic seismic analysis of a multistorey building, International Journal of Research in Engineering science and Technology, Volume: 02 Issue: 01 | July2015.

[4] Bahador Bagheri, Ehsan Salimi Firoozabad and Mohammadreza Yahyaei, Comparative study of the static and dynamic analysis of multistorey irregular building, International Journal of Civil, Environment, Structural, Construction and Architectural Engineering, Volume: 06 Issue: $11 \mid 2012$.

[5] Mr. S. Mahesh, Mr. Dr. B. Pandurangarao, Comparison of analysis and design of regular and irregular configuration of multistrorey building in various seismic zones and various types of soils using ETABS and STAAD,IOSR Journal of Mechanical and Civil Engineering, Volume: 11 Issue: 06 | Dec $-2014$.

[6] E. Pavan Kumar, A. Naresh, M. Nagajyothi, M. Rajasekhar, Earthquake analysis of multistoried residential building - A case study, International Journal of Engineering, Research and Applications, Volume: 04 Issue: 11 | Nov-2014

[7] Nilanjan Tarafdar, Kamlesh Bhowmik and K. V. Naveen Kumar, Earthquake resistant techniques and analysis of tall buildings, International Journal of Research in Engineering \& Technology, Volume: 04 Issue: 13 | Dec-2015.

[8] Bahador Bagheri, Krishna Nivedita and Ehsan Salimi Firoozabad, Comparative damage assessment of irregular building based on static and dynamic analysis, International Journal of Civil and Structural Engineering, Volume: 03 Issue: 03 | 2013

[9] Santosh Kumar Adhikari and Dr. K. Rajasekhar, Comparative static and dynamic study on seismic analysis of uniform and nonuniform column sections in a building, International Journal of Innovative Research in Science, Engineering \& Technology, Volume: 04 Issue: 08 | Aug-2015.

[10] Pankaj Agrawal, Manish shrikhande, Earthquake resistant design of structure.
[11] S.K. Duggal, Earthquake resistant design of structure.

[12] Chopara A. K, Dynamic of structure

[13] IS 1893(part 1) (2002), Indian Standard Code of Practice for Criteria for Design of Earthquake Resistant Structures, Bureau of Indian Standards, New Delhi.

[14] IS 456:2000, Indian Standard Code of Practice for Criteria for Plain and Reinforcement concrete, Bureau of Indian Standards, New Delhi. 